\title{
THE RELATIONSHIP BETWEEN LENS OPACITIES AND COLOR DISCRIMINATION ABILITY IN CATARACT PATIENTS
}

\author{
ALIE SOLAHUDDIN ${ }^{1}$, THEODORUS $^{2}$, DIAN ARIANI ${ }^{3 *}$ \\ ${ }^{1}$ Departement of Ophthalmology, Faculty of Medicine, Moeh.Hoesin Hospital, Sriwijaya University, Indonesia. ${ }^{2}$ Medical Research Unit, \\ Faculty of Medicine, Sriwijaya University, Indonesia. ${ }^{3}$ Fellow Students, Department of Ophthalmology, Faculty of Medicine, Sriwijaya \\ University, Indonesia. Email: dr.dian.ariani@gmail.com \\ Received: 05 September 2017, Revised and Accepted: 22 November 2017
}

ABSTRACT

Objective: To determine the relationship between lens opacities and color discrimination ability in cataract patients at the Special Eye Hospital in Palembang.

Methods: A case study was undertaken in January to March 2017 at the Special Eye Hospital in Palembang. There were 80 cataract patients who met the inclusion and exclusion criteria. The relationship between lens opacities and color discrimination ability was analyzed using Spearman rho correlation test using SPSS version 18.0.

Results: About $51.2 \%$ out of 80 cataract patients, most patients were diagnosed with nucleotide cataract with the majority degree of opacities is Grade III (50\%). Average of total error score was 51.425 51,441 (range 0-312). The correlation test results showed a significant weak positive correlation between lens opacities and color discrimination ability $(r=0.376 ; p=0.001 ; n=80)$ where the percentage of effect of lens opacities to color discrimination ability was only $7.9 \%\left(\mathrm{R}^{2}=0.079\right)$.

Conclusion: There was a significant weak positive correlation between lens opacities and color discrimination ability.

Keywords: Cataract, Lens opacity, Color discrimination ability, Spearman rho, Total error score, Correlation test.

(C) 2018 The Authors. Published by Innovare Academic Sciences Pvt Ltd. This is an open access article under the CC BY license (http://creativecommons. org/licenses/by/4. 0/) DOI: http://dx.doi.org/10.22159/ajpcr.2018.v11i2.22384

\section{INTRODUCTON}

The main function of the lens is to transmit light and focus the light to fall right in the retina. To support the function required a transparent lens. The transparency of the lens depends on the orderly arrangement of lens and protein cells [1].

Cataracts are lens opacities that inhibit normal vision. Although cataracts are mostly age-related, children may also be born with cataracts, or acquired after trauma, inflammation, and some other diseases [1-7]. Pathogenesis of senile cataracts includes many factors, one of the main causes is the degeneration of lens proteins caused by aging, which triggers the occurrence of symptoms such as opacities, dimness of sight, watery eyes, and double vision $[7,8]$.

In the advance phase, transparent lens changes from transparent to yellowish and brownish. Along with the development of cataracts to a more advanced level, the lens will become completely murky and trigger the occurrence of blindness. Heavier cataracts can affect the occurrence of visual disturbances and the ability to discriminate colors, in particular color discrimination in the red and purple spectrum, and the blue and green color spectrum [7,9]. This condition is due to an increase in optical density of the lens causing a change in transmission light through the lens, and the more yellow the color of the lens, the more absorbed light with a short wavelength with a spectrum between 450 and $470 \mathrm{~nm}[10]$.

Data available for color discrimination ability in other types of cataracts are still few, and there has been no previous research at the Special Eye Hospital of the people in South Sumatra became the basis of consideration of research on the relationship of lens opacities and color discrimination ability.

\section{METHODS}

A descriptive research in the form of serial cases was undertaken in January to March 2017 at Special Eye Hospital in Palembang. There were 80 cataract patients who fulfilled the inclusion and exclusion criteria. The protocol has been approved of Ethics Committee, Faculty of Medicine Sriwijaya University.

Examination of cataract grade was performed to determine lens opacities value, while the color discrimination examination was performed using Farnsworth Munsell 100 Hue.

The frequency and distribution of cataract patient's data are described in univariate table form, and the relationship between lens opacities and color discrimination ability is analyzed using Spearman rho correlation test. Data analysis was performed using SPSS version 18.0.

\section{RESULT}

In the period January-February 2017 there are 80 cataract patients who meet the criteria of inclusion and exclusion.

Table 1 summarize that out of 80 cataract patients, there are 40 male $(50 \%)$ and 40 female (50\%) with average age 63.58 \pm 9.508 years (age range 50-84 years). Patients with cataracts in this study the majority of low education as much as $63.8 \%$ (no school, elementary and junior high) and the majority do not work as much as $56.2 \%$ (housewives and pensioners).

The ophthalmological characteristics of the research subjects are shown in Table 2. In this study, the location of cataracts in the right eye was 36 people (45\%) and the left eye of 44 people (55\%). 
Patients were diagnosed with nuclear cataracts of 41 patient (51.2\%), followed by cataract mixture of 30 patient (37.5\%), and cortical cataracts and subscapularis posterior each of 6 patient $(7.5 \%)$ and 3 patient (3.8\%) with the majority degree of opacities lens is Grade III $(50 \%)$.

Ability of color discrimination of cataract is 48 medium discrimination (60\%), followed by superior discrimination 21 patient $(26.2 \%)$, and low color discrimination of 11 patient (13.8\%), with mean total error score (TES) equal to $51.425 \pm 51.441$ (total error range 0 through 312 ).

Table 3 summarized a no significant weak negative correlation between visus and lens opacities ( $\mathrm{r}=-0.071 ; \mathrm{p}=0.531 ; \mathrm{n}=80)$ and a no significant weak positive correlation between virus and color discrimination ability ( $r=0.167 ; p=0.138 ; n=80)$.

Table 1: Characteristics demographics of research subject

\begin{tabular}{ll}
\hline Characteristics & Total (\%) \\
\hline Age (years), mean \pm SD & $63.58 \pm 9.508(50-84)$ \\
Sex n (\%) & $40(50.0)$ \\
$\quad$ Male & $40(50.0)$ \\
Female & \\
Education, n (\%) & $12(15.0)$ \\
$\quad$ No school & $32(40.0)$ \\
Elementary school & $7(8.8)$ \\
Junior high school & $17(21.2)$ \\
Senior high school & $12(15.0)$ \\
Bachelor degree & $32(40.0)$ \\
Occupation, n (\%) & $24(30.0)$ \\
Housewives & $11(13.8)$ \\
Private employees & $13(16.2)$ \\
Laborers/farmers & \\
Pensioners & \\
\hline
\end{tabular}

Table 2: Ophthalmological characteristics of research subjects

\begin{tabular}{ll}
\hline Characteristics & Total \\
\hline TES, mean \pm SD & $51.425 \pm 51.441(0-312)$ \\
Location of cataract, n (\%) & $36(45.0)$ \\
$\quad$ Right eye & $44(55.0)$ \\
$\quad$ Left eye & $41(51.2)$ \\
Type of cataract, n (\%) & $6(7.5)$ \\
$\quad$ Nuclear cataract & $3(3.8)$ \\
$\quad$ Cortical cataract & $30(37.5)$ \\
Subscapularis posterior cataract & \\
$\quad$ Mixture cataract & $6(7.5)$ \\
Degree of cataract n (\%) & $33(41.2)$ \\
$\quad$ Grade I & $40(50.0)$ \\
Grade II & $1(1.2)$ \\
Grade III & $11(13.8)$ \\
$\quad$ Grade IV & $48(60.0)$ \\
Color discrimination ability, TES n (\%) & $21(26.2)$ \\
$\quad$ Low & \\
Medium & \\
Superior &
\end{tabular}

TES: Total error score

Table 3: Analysis of virus with opacities of lens and color discrimination ability in cataract patients

\begin{tabular}{lllll}
\hline Korelasi & N & Mean \pm SD & R & p \\
\hline Virus & 80 & $0.913 \pm 0.274$ & $-0.071^{*}$ & $0.531^{*}$ \\
Lens opacities & 80 & $2.45 \pm 0.654$ & & \\
Virus & 80 & $0.913 \pm 0.274$ & $0.167^{*}$ & $0.138^{*}$ \\
Color discrimination & 80 & $51.425 \pm 51.441$ & & \\
ability & & & & \\
\hline
\end{tabular}

*Uji Spearman, $P=0.05$
From the analysis of linear regression obtained $R^{2}=0.010$. This result showed that the percentage of virus effect on lens opacities is only $1 \%$ as well as the percentage effect of virus on color discrimination ability is only $1 \%$.

Table 4 found a significant weak positive correlation between lens opacities and color discrimination ability ( $\mathrm{r}=0.376 ; \mathrm{p}=0.001 ; \mathrm{n}=80$ ). Moderate positive correlation between lens opacities and color discrimination ability in nuclear cataract $(r=-0.590 ; p=0.000 ; n=71)$, nonsignificant weak negative correlation between lens opacities and color discrimination ability in cortical cataract $(r=-0.269 ; p=0.193$; $\mathrm{n}=25$ ) and nonsignificant weak negative correlation between lens opacities and color discrimination ability in subcapsularis posterior cataract $(r=-0.262 ; p=0.327 ; n=16)$.

From the analysis of linear regression obtained $R^{2}=0.079$. This result showed the percentage of effect of lens opacities to color discrimination ability only equal to $7.9 \%$, where effect of lens opacities to color discrimination ability in nuclear cataracts only $20 \%$, effect of lens opacities to color discrimination ability in cortical cataract only equal to $6.4 \%$ and the effect of lens opacities on color discrimination abilities in posterior subcapsular cataracts of only $6.9 \%$ (Table 5 ).

In this study, the most common hue/color impacts affected by cataract were blue green-blue by 53 people (39.3\%) and green yellow-green by 43 people (31.9\%), while the least affected hue/color by cataract

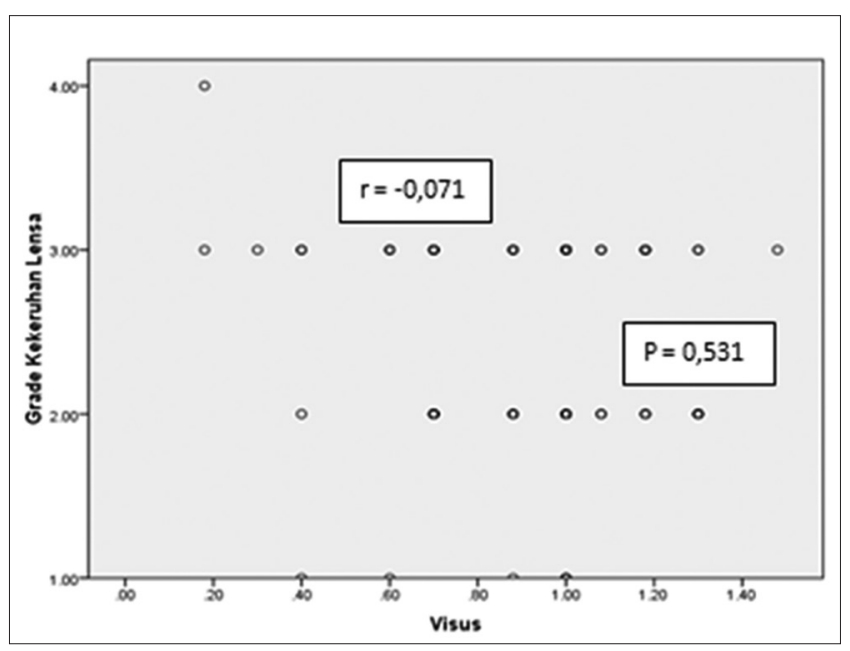

Fig. 1: Correlation of virus with opacities on cataract patients

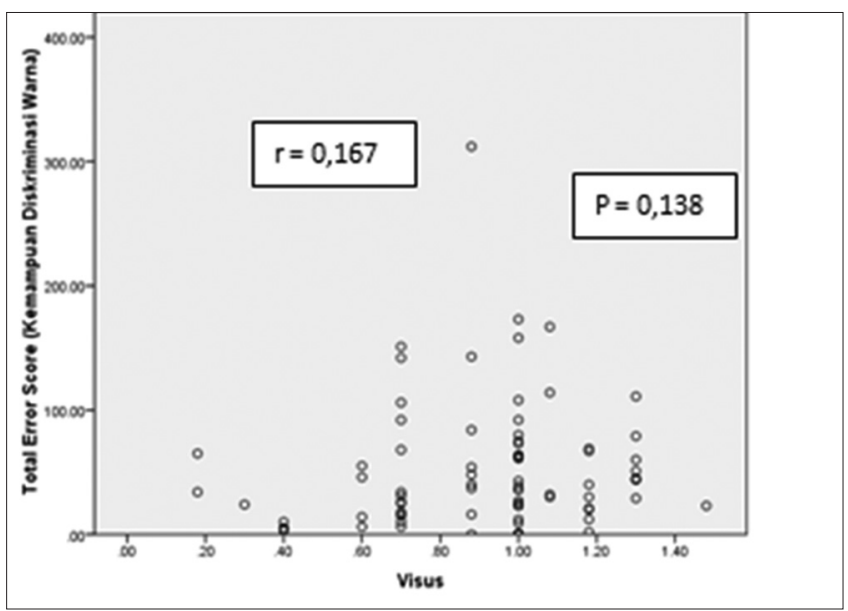

Fig. 2: Correlation of virus with color discrimination on cataract patients 
Table 4: Analysis of opacities of lens and color discrimination ability in cataract patients

\begin{tabular}{|c|c|c|c|c|c|}
\hline Type of cataract & Correlation & $\mathbf{N}$ & Mean $\pm S D$ & $\mathbf{R}$ & $\mathbf{p}$ \\
\hline \multirow[t]{2}{*}{ All type } & Lens opacities & 80 & $2.45 \pm 0.654$ & $0.376^{*}$ & $0.001^{*}$ \\
\hline & Color discrimination ability & 80 & $51.425 \pm 51.441$ & & \\
\hline \multirow[t]{2}{*}{ Nuclear } & Lens opacities & 71 & $2.23 \pm 0.637$ & $0.590^{*}$ & $0.000 *$ \\
\hline & Color discrimination ability & 71 & $53.75 \pm 53.76$ & & \\
\hline \multirow[t]{2}{*}{ Cortikal } & Lens opacities & 25 & $2.6 \pm 0.577$ & $-0.269 *$ & 0.193* \\
\hline & Color discrimination ability & 25 & $63.12 \pm 58.84$ & & \\
\hline Subcapsularis & Lens opacities & 16 & $2.5 \pm 0.516$ & $-0.262^{*}$ & $0.327^{*}$ \\
\hline
\end{tabular}

*Uji Spearman, $P=0.05$, SD: Standard deviation

Table 5: Comparison of correlation and effect of lens opacities with color discrimination ability in each cataract morphology

\begin{tabular}{llll}
\hline Morphology & N & Correlation (r) & $\mathbf{R}^{\mathbf{2}}$ \\
\hline Nuclear cataract & 71 & 0.590 & 0.200 \\
Cortical cataract & 25 & -0.269 & 0.064 \\
Subcapsularis posterior cataract & 16 & -0.262 & 0.069 \\
\hline
\end{tabular}

Table 6: Type of hue/color error in cataract patient

\begin{tabular}{ll}
\hline Hue/color error & Total (\%) \\
\hline Blue green-blue & $53(39.3)$ \\
Green-blue green & $3(2.2)$ \\
Green yellow-green & $43(31.9)$ \\
Purple-red purple & $9(6.7)$ \\
Purple blue-purple & $2(1.5)$ \\
Red-yellow red & $15(11.1)$ \\
Red purple-red & $2(1.5)$ \\
Yellow-green yellow & $4(3.0)$ \\
Yellow red-yellow & $4(3.0)$ \\
Total & $135(100)$ \\
\hline
\end{tabular}

Table 7: Type of hue/color error based on cataract morphology

\begin{tabular}{llll}
\hline Hue/color error & $\mathbf{n}(\%)$ & & \\
\cline { 2 - 4 } & Nuclear & Cortical & $\begin{array}{l}\text { Subcapsularis } \\
\text { posterior }\end{array}$ \\
\hline Blue green-blue & $13(28.3)$ & $52(41.6)$ & $10(37)$ \\
Green-blue green & $2(4.3)$ & $3(2.4)$ & $0(0)$ \\
Green yellow-green & $17(37.0)$ & $38(30.4)$ & $7(25.9)$ \\
Purple-red purple & $3(6.5)$ & $9(7.2)$ & $3(11.1)$ \\
Purple blue-purple & $0(0)$ & $2(1.6)$ & $0(0)$ \\
Red-yellow red & $8(17.4)$ & $12(9.6)$ & $4(14.8)$ \\
Red purple-red & $0(0)$ & $2(1.6)$ & $0(0)$ \\
Yellow-green yellow & $2(4.3)$ & $4(3.2)$ & $1(3.7)$ \\
Yellow red-yellow & $1(2.2)$ & $3(2.4)$ & $2(7.4)$ \\
Total & $46(100)$ & $125(100)$ & $27(100)$ \\
\hline
\end{tabular}

is purple blue-purple dan red purple-red each of 2 people $(1.5 \%)$ (Table 6).

From Table 7 can be seen on the most commonly affected hue/color error in nuclear cataract is blue green-blue hue as many as 52 people $(41.6 \%)$. In the cortical cataract, the most affected hue/color are green, yellow-green hue is 17 patient $(37 \%)$ whereas in the posterior subcapsularis cataract the most affected hue/color is the blue greenblue hue of 10 patient (37\%).

\section{DISCUSSION}

The most cataract morphology type was $51.2 \%$ of nuclear cataracts followed by mixture cataracts of $37.5 \%$. The results of this study were not much different from the Valero study in Spain in 2001 where the majority of cataract patients had a nucleus morphology type of $50 \%$ followed by mixed cataracts of $41.4 \%$ [11].

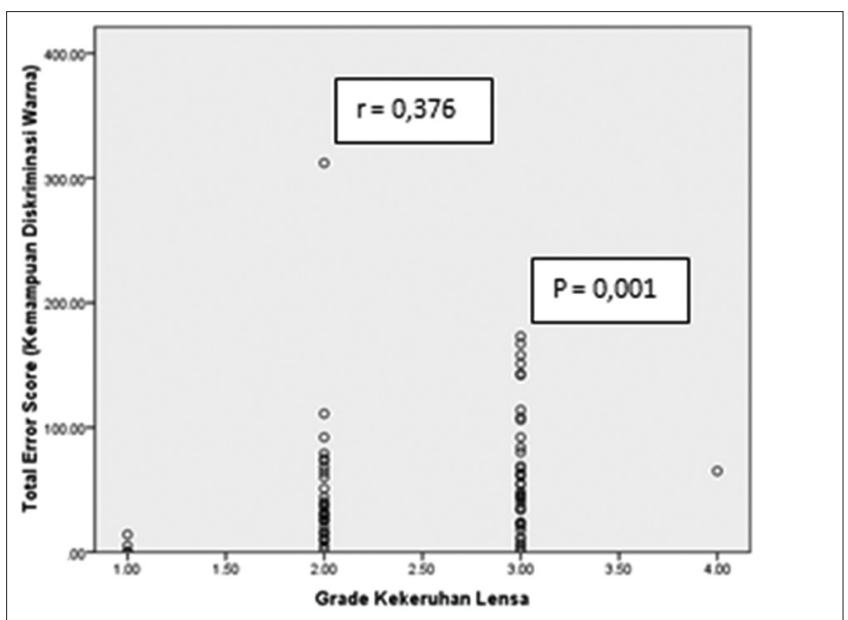

Fig. 3: Correlation of lens opacities and discrimination on cataract patients

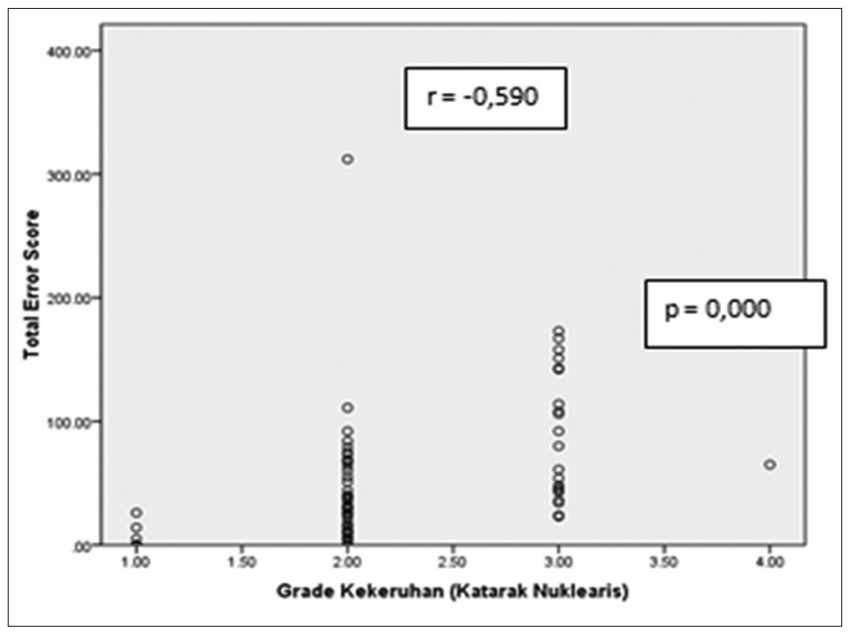

Fig. 4: Correlation of lens opacities and color discrimination on nuclear cataract patients

The Farnsworth color discrimination test is one of the tests to assess color discrimination, so as to separate patients with normal color vision separated into superior, medium and low color discriminations [12-20]. Scores or error values are calculated based on the distance between errors two panels. The sum of the error values of the entire set of panels is the TES [12-21].

In this research, the mean TES of cataract patients was $51.425 \pm 51.441$ with range $0-312$ whereas $60 \%$ had medium discrimination ability (total error range 20-100), 26.2\% superior discrimination ability (total error range $0-20$ ) and $13.8 \%$ low discrimination ability (TES $>100$ ). Most hue/color errors are blue green-blue and green yellow- 


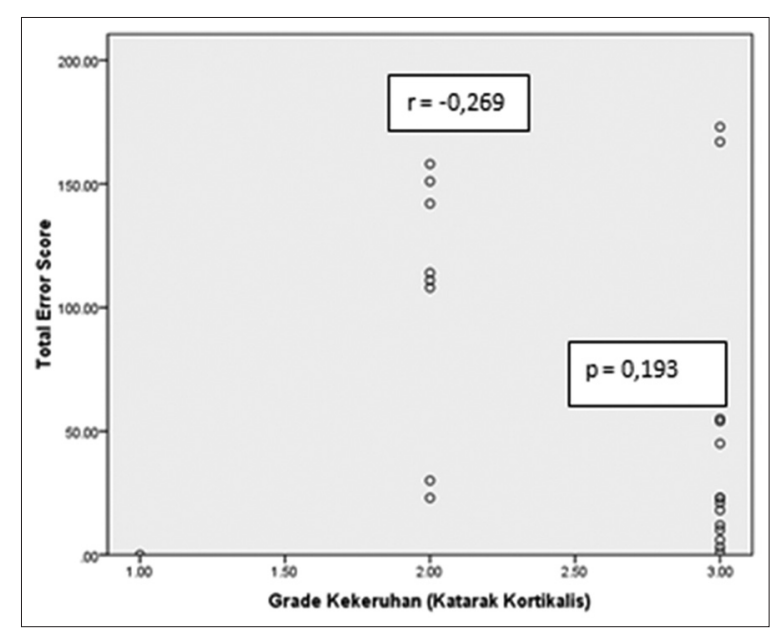

Fig. 5: Correlation of lens opacities and color discrimination on cortical cataract patients

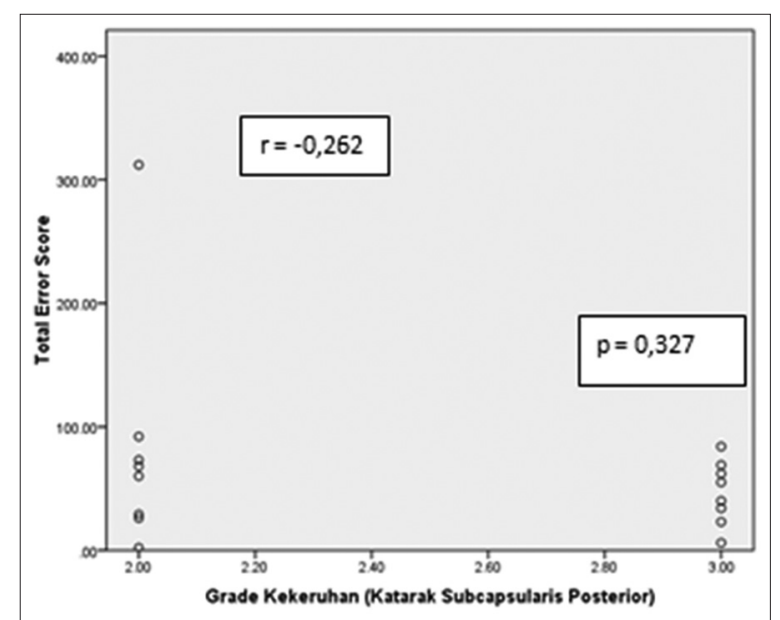

Fig. 6: Correlation of lens opacities and color discrimination on subcapsularis posterior cataract patients

green in both the nuclear, posterior cortical and subcapsularis cataracts.

The average TES in this study is $51.425 \pm 51.441$; this value is lower than the mean TES in Kessel research in 1999 where got a score equal to 83 \pm 79.43 while Erb research in 1997 in healthy person obtained TES higher than in patients with cataracts of $61.4 \pm 3.43$.48. This difference in results indicates that color discrimination ability is not only impacted by lens opacities alone but is also affected by retinal damage, damage to the optic nerve and disturbance to the refractive medium.

In this research, there was a significant positive correlation between lens opacities and color discrimination ability $(r=0.376 ; p=0.001 ; n=80)$ where percentage affect of lens opacity to color discrimination ability was only 7.9\%. If the correlation and the affect of lens opacities to color discrimination ability for based on the morphology of cataracts then obtained the result that the nuclear cataract has the correlation and the greatest influence is the correlation is with the influence of $20 \%$.

The ability of color vision is a reflection of the good photoreceptor function located in the retina. Any disease affecting photoreceptors and optic nerve fibers can cause changes in color perception. Coellner's rule states that damage from the retina causes a tritan defect, and damage to the optic nerve causes a red-green defect. Changes in color vision acquired unlike congenital color changes in color that can occur in several types and there is a degree of severity during disease. Visual impairment and pre-existing field of view can make color vision assessment difficult. 19-24 in addition, interference with the refraction medium may inhibit the entry of light impulses into the retina, thus affecting a person's ability to discriminate color [2].

\section{CONCLUSION}

There is a significant weak positive correlation between lens opacities and color discrimination ability in cataract patients where the greatest correlation and effect is the nuclear cataract.

\section{ACKNOWLEDGMENT}

We would like to thank Dr. Rachmat Hidayat, M.Sc, and Dr. Debby Handayati, M.Kes, for assistance the publication of this paper.

\section{REFERENCES}

1. Fong KC. The Ageing Lens and Classification of Cataracts. USA: Elsevier; 2008. p. 2-14.

2. American Academy of Ophthalmology. Lens and Cataract. San Francisco: AAO Publisher; 2014.

3. Kanski JJ. Clinical Ophthalmology: A Systemic Approach. $7^{\text {th }}$ ed. Philadelphia, PA: Mosby; 2011.

4. World Health Organization. Priority Eye Disease; 2016. Available from: http://www.diaksesdariwww.who.orgtanggal. [Last accessed on 2016 Dec 12].

5. National Eye Institute. Statistic and Data of Cataracts; 2010. Available from: http://www.diaksesdariwww.nei.comtanggal. [Last accessed on 2016 Dec 12].

6. Chew M, Chiang PP, Zheng Y, Lavanya R, Wu R, Saw SM, et al. The impact of cataract, cataract types, and cataract grades on vision-specific functioning using Rasch analysis. Am J Ophthalmol 2012;154:29-38.e2.

7. Ao $\mathrm{M}$, Chen X, Huang $\mathrm{C}, \mathrm{Li} \mathrm{X}$, Hou Z, Chen X, et al. Color discrimination by patients with different types of light-filtering intraocular lenses. J Cataract Refract Surg 2010;36:389-95.

8. Brown NA. The morphology of cataract and visual performance. Eye (Lond) 1993;7:63-7.

9. Chen P, Imaizumi S, Lin DP, Suke-Hito KU, Shinichi KO, Haruo HI, et al. Visual acuity, color discrimination, and quality of life in patients with cataract: Towards a comfortable lifestyle. Int J Affect Eng 2016;15:1-8

10. Kim BG, Han J, Park S. Computer simulation for gradual yellowing of aged lens and application for test devices. JOSK 2013;17:344-9.

11. Noran NH, Nooriah S, dan Mimiwati Z. The association between body mass index and age related cataract. Med J Malaysia 2007;62:49-52.

12. Winkler BS, Arnold MJ, Brassell MA, Puro DG. Energy metabolism in human retinal Müller cells. Available from: http://www.PubMed/NCBI. fcgi.html. [Last accessed on 2009 Jun 26].

13. Strauss $\mathrm{O}$. The retinal pigment epithelium in visual function. Physiol Rev 2005;85:845-81.

14. Twinkle P, Vanathi M, Ghose S, Dada T, Venkatesh P. Colour Vision Revisited-Delhi Journal Ophthalmolol. New Delhi: AIIMS; 2014.

15. Almog Y, Nemet A. The correlation between visual acuity and color vision as an indicator of the cause of visual wavelength discrimination. J Optical Am A 2001;18:310-8.

16. Verriest G, Van Laethem J, Uvijls A. A new assessment of the normal ranges of the Farnsworth-Munsell 100-hue test scores. Am J Ophthalmol 1982;93:635-42.

17. Lugo M, Tiedman JS. Computerized scoring and graphing of the Farnsworth-Munsell 100-hue color vision test. Am J Ophthalmol 1986;101:469-74.

18. Barton FB, Fong DS, Knatterud GL. Classification of FarnsworthMunsell 100-hue test results in the early treatment diabetic retinopathy study. Ophthalmology 1991;98:741-56.

19. Kraft JM, Werner JS. Aging and the saturation of colors 2. Scaling of color appearance. J Opt Soc Am A Opt Image Sci Vis 1999;16:231-5.

20. Shinomori K, Schefrin BE, Werner JS. Age-related changes in wavelength discrimination. J Opt Soc Am A Opt Image Sci Vis 2001;18:310-8.

21. Zlatkova MB, Coulter EE, Anderson RS. The effect of simulated lens yellowing and opacification on blue-on-yellow acuity and contrast sensitivity. Vision Res 2006;46:2432-42. 